\title{
Transfusion of sex-mismatched and non-leukocyte-depleted red blood cells in cardiac surgery increases mortality
}

\author{
Henrik Bjursten, $\mathrm{MD}, \mathrm{PhD},{ }^{\mathrm{a}}$ Alain Dardashti, $\mathrm{MD}, \mathrm{PhD},{ }^{\mathrm{b}}$ Jonas Björk, $\mathrm{PhD},{ }^{\mathrm{c}}$ Per Wierup, $\mathrm{MD}, \mathrm{PhD},{ }^{\mathrm{a}}$ \\ Lars Algotsson, $\mathrm{MD}, \mathrm{PhD},{ }^{b}$ and Per Ederoth, $\mathrm{MD}, \mathrm{PhD}^{\mathrm{b}}$
}

\section{ABSTRACT}

Objective: To examine the mortality risk of blood transfusions when donor information, postdonation treatment, and a wide selection of risk factors are taken into account.

Methods: A retrospective study was performed on 9907 patients who underwent coronary artery bypass grafting and/or aortic valve replacement. Several transfusion-related risk factors, including age of blood products, sex of donor, $\mathrm{ABO}$ group, $\mathrm{Rh}$ group, posttransfusion treatment, and sex matching, were included in the analysis. A wide selection of preoperative comorbidities were included as well. A Cox proportional hazards analysis was performed to determine significant risk factors. Patients were followed for a period of up to 12 years posttransfusion.

Results: We found an excess mortality for transfusions of sex-mismatched red blood cells (RBCs) per unit transfused (hazard ratio [HR], 1.083; 95\% confidence interval $[\mathrm{CI}] 1.028-1.140 ; P=.003)$. In addition, we found a significant risk during the first year for transfusing 1 to 2 units of non-leukocyte-depleted RBCs (HR, 1.426; 95\% CI, 1.004-2.024; $P=.047)$. Transfusion of 1 to 2 units of leukocyte-depleted RBCs was not associated with increased risk (HR, 0.981; 95\% CI, 0.866-1.110; $P=$ not significant). The age of blood products was not associated with increased mortality.

Conclusions: In this large retrospective study, transfusion of non-sex-matched RBCs was associated with increased mortality. In addition, in patients receiving small amounts of blood, leukocyte depletion of RBCs had a beneficial effect on patient survival. (J Thorac Cardiovasc Surg 2016;152:223-32)

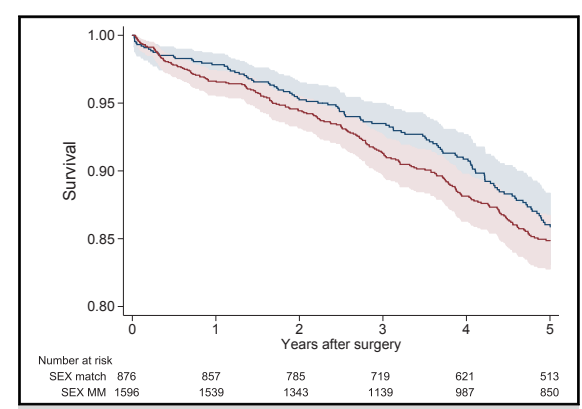

Categorized hazard ratio for leukocyte-depleted and non-leukocyte-depleted blood.

Central Message

Transfusion of red blood cells does not impact survival as long as sex-mismatched blood and non-leukocyte-depleted blood are avoided.

\section{Perspective}

Recent randomized trials have shown that a liberal transfusion threshold, or transfusion of older blood, does not have a negative impact on short-term survival. The long-term risks of transfusion are still being debated, however. The present study tries to shed some more light on this area.

See Editorial Commentary page 233.

See Editorial page 18.
Transfusion of blood products has been associated with increased short- and long-term mortality after cardiac surgery. Suggested risk factors include transfusion of packed red blood cells (RBCs), transfusion of plasma, and the age of transfused RBCs. ${ }^{1-4}$

\footnotetext{
From the Departments of ${ }^{\mathrm{a}}$ Cardiothoracic Surgery and ${ }^{\mathrm{b}}$ Anesthesiology and Intensive Care, Clinical Sciences and ${ }^{c}$ Department of Occupational and Environmental Medicine, Lund University, Lund, Sweden.

This research was made possible by Lund University Hospital funds.

Received for publication June 12, 2015; revisions received Dec 11, 2015; accepted for publication Dec 14, 2015; available ahead of print Feb 10, 2016.

Address for reprints: Henrik Bjursten, MD, PhD, Department of Cardiothoracic Surgery, Clinical Sciences, Skane University Hospital/Lund, SE-221 85 Lund, Sweden (E-mail: henrik.bjursten@med.lu.se).

$0022-5223 / \$ 36.00$

Copyright (c) 2016 by The American Association for Thoracic Surgery

http://dx.doi.org/10.1016/j.jtcvs.2015.12.022
}

Previous studies have focused on selected risk factors of transfusion, rather than addressing the heterogeneity of transfusion in their analysis. Each blood product has several properties that could potentially affect outcome. To date, mainly the age of RBCs and sex of the plasma donor have been investigated in detail. Factors such as ABO group, $\mathrm{Rh}$ profile, and sex of the RBC donor generally have been overlooked, as has the variation in postdonation treatment

Scanning this QR code will take you to supplemental figures for this article.

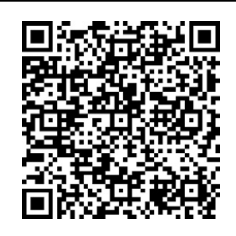




$$
\begin{aligned}
& \text { Abbreviations and Acronyms } \\
& \begin{aligned}
\text { AVR } & =\text { aortic valve replacement } \\
\mathrm{CABG} & =\text { coronary artery bypass grafting } \\
\mathrm{CI} & =\text { confidence interval } \\
\mathrm{COPD} & =\text { chronic obstructive pulmonary disease } \\
\mathrm{CRP} & =\text { C-reactive protein } \\
\mathrm{eGFR} & =\text { estimated glomerular filtration rate } \\
\mathrm{HR} & =\text { hazard ratio } \\
\mathrm{ICU} & =\text { intensive care unit } \\
\mathrm{RBC} & =\text { red blood cell }
\end{aligned}
\end{aligned}
$$

of blood. For instance, leukocyte depletion of RBCs and different methods of storing plasma all alter the properties of the blood product. All of these factors could have an adverse effect on the recipient.

Relevant comorbidities that can increase both the risk of transfusion and the risk of mortality have not been adequately considered, thereby missing the casual relationship between a preexisting condition and mortality and instead associating the transfusion with mortality. Although many studies have included renal function in their analyses, it has been mostly in the inexact form of serum creatinine level or a dichotomous variable., ${ }^{5,6}$ Anemia and markers of inflammation, both markers for disease, generally have not been included.

Consequently, the aim of the present study was to examine the risk profile of transfusions in terms of longterm mortality when donor information, postdonation treatment of blood, and a broad selection of confounding risk factors are taken into account. By including a wide variety of risk factors, we wanted to avoid statistical confounding and covariation, which are risks when attempting to retrospectively address an outcome that is potentially associated with numerous overlapping independent variables.

\section{METHODS \\ Study Design}

This retrospective study included patients who underwent surgery at the Department of Cardiothoracic Surgery at Lund University Hospital between January 1, 2002, and December 31, 2012. Data were collected from 4 principal sources. Clinical data were retrieved from the in-house clinical database, in which relevant clinical perioperative information is collected during a patient's hospital stay. The databases of the hospital's clinical chemistry laboratory and blood bank served as the second and third sources of data. Data on time of death, but not on cause of death, were obtained from the Swedish Tax Agency, covering deaths up to December 2013, defining the follow-up period of 1 to 12 years. The study protocol was approved by the local Ethics Committee.

\section{Patient Inclusion and Exclusion}

Data were gathered on all patients who underwent coronary artery bypass grafting (CABG; $\mathrm{n}=8682$ ), aortic valve replacement (AVR; $\mathrm{n}=1411)$, or both CABG and AVR $(\mathrm{n}=1232)$ during the study period (total, $\mathrm{n}=11,325)$. Patients were excluded if they underwent repeat procedures $(\mathrm{n}=327)$; underwent emergency surgery, defined as surgery within 1 hour of the decision to operate $(n=212)$; received a life-saving transfusion (defined as 8 or more units of RBCs; $n=613$ ); underwent off-pump surgery $(\mathrm{n}=218)$; or died during the first 7 days after surgery $(\mathrm{n}=48)$. A total of 9907 patients (CABG, $\mathrm{n}=7696$; AVR, $\mathrm{n}=1216$; AVR + CABG, $n=995$ ) were finally included in the analysis.

\section{Completeness and Reliability of the Data}

Preoperative characteristics and intraoperative information were entered into the in-house database by each surgeon (near 100\% completion rate), and postoperative data had a completion rate of $88 \%$ to $100 \%$. Information on deaths was obtained indirectly from the Swedish Tax Authority, which lacks data only in exceptional cases such as emigration and patients lost to follow-up. The emigration rate for all Swedes in this age category is approximately $0.1 \%$ per year. ${ }^{7}$ Transfusion of blood products was defined as a transfusion during surgery or during the postoperative stay. Transfusion data were retrieved from the blood bank's quality-controlled database (deemed $100 \%$ accurate). Laboratory parameters were retrieved electronically from medical records. When data were missing or extreme outliers were identified, patient records were read in a first attempt to complete the data. After this, preoperative creatinine values were still missing for 214 patients, and thus these values were imputed based on the levels on the first postoperative day. ${ }^{8}$ Missing preoperative data for hemoglobin concentration $(n=208)$ and preoperative leukocyte count $(n=757)$ were imputed from mean values for the other cases. Missing preoperative C-reactive protein $(\mathrm{CRP})$ values $(\mathrm{n}=833)$ were imputed from the median value for the rest of the cases. For missing dichotomous variables, a mode value substitution was used.

Renal function was expressed as the estimated glomerular filtration rate (eGFR) and calculated according to the Chronic Kidney Disease Epidemiology Collaboration's formula. ${ }^{9}$

\section{Transfusion Practices During the Study Period}

No predefined limits for RBC transfusion were applied during the study period, and indications for transfusion for each patient were determined by the surgeon or the physician in charge of postoperative care. The attitude toward RBC transfusion varied during the study period, with periods of more liberal treatment and more restrictive treatment. In addition, the use of plasma and platelets changed during the study period, owing to, for example, changes in preoperative anticoagulants and/or more extensive use of procoagulant products (eg, fibrinogen and factor concentrates).

\section{Independent Variable Selection and Statistical Analysis}

The variables used for survival analysis were based on frequently found predictors for decreased survival in recent survival studies focusing on renal function or RBC transfusion in cardiac surgery and available laboratory parameters that could reflect underlying disease. ${ }^{5,10-15}$ For transfusion, we retrieved as many parameters as possible related to the quality of the blood product. The following variables were entered as dichotomous variables: sex, diabetes, chronic obstructive pulmonary disease (COPD), history of cerebrovascular disease, peripheral vascular disease, left ventricular ejection fraction $30 \%$ to $50 \%$, left ventricular ejection fraction $<30 \%$, recent myocardial infarction, unstable angina, known pulmonary hypertension (systolic blood pressure $>60 \mathrm{mmHg}$ ), acute coronary symptoms, preoperative dialysis, previous percutaneous coronary intervention, use of cardiopulmonary bypass, use of an intraaortic balloon pump before surgery, use of an intra-aortic balloon pump after surgery, postoperative sepsis, postoperative stroke, postoperative atrial fibrillation, perioperative myocardial infarction, and reoperation for bleeding or mediastinitis. Age, perfusion time, cross-clamp time, perfusion 
time minus cross-clamp time, time on a ventilator in the intensive care unit (ICU), and body mass index were entered as continuous variables. Preoperative renal function (expressed as preoperative eGFR), hemoglobin, the logarithm of plasma CRP, plasma alanine aminotransferase, plasma aspartate aminotransferase, plasma leukocyte count, and platelet count were also entered as continuous variables. A dichotomous variable was constructed and used for early period (2002-2006) versus late period (2007-2012).

The following variables were constructed for RBCs: number of leukocyte-depleted RBC units, non-leukocyte-depleted RBC units, RBC units with an $\mathrm{ABO}$ mismatch (defined as transfusion outside the recipient's blood group but within transfusion rules), $\mathrm{RBC}$ units with an $\mathrm{Rh}$ (D-antigen) mismatch, RBC units with a sex mismatch between donor and recipient, $\mathrm{RBC}$ units that came from a female donor, $\mathrm{RBC}$ units that were not produced in-house, accumulated storage time for all RBC units given to the patient (per 10 days), and RBC units that had been stored for longer than 14 days. The following variables were constructed for plasma: units of fresh frozen plasma, unit of fresh plasma, units of Octaplas (Octapharma, Stockholm, Sweden), units of plasma with an ABO mismatch, units with an Rh mismatch, units with a sex mismatch, units from a female donor, units that were not produced in-house, accumulated storage time for the plasma given to the patient (per 10 days), and units of plasma that had been stored for longer than 14 days. The following variables were constructed for platelets: units of platelets, units of platelets with an $\mathrm{ABO}$ mismatch, units with an $\mathrm{Rh}$ mismatch, units from female donor, units that were not produced in-house, accumulated storage time for the platelets given to the patient (per 5 days), and units that had been stored for longer than 7 days. Patient blood group (A, B, $\mathrm{AB}$, or $\mathrm{O}$ ) was entered as a dichotomous variable, as was patient $\mathrm{Rh}$ group $(+$ or -$)$.

\section{Model Building}

A Cox proportional hazards model was used to identify the factors affecting long-term survival. Primary model building was performed by a backward stepwise elimination procedure with the aforementioned variables (excluding variables with fewer than 30 valid observations) for the entire period ( $0-12$ years). Variables with a $P$ value $<.05$ were retained in the model together with the numbers of RBC, plasma, and platelets units regardless of their level of significance. The proportional hazards assumption was tested using scaled Schoenfeld residuals.

Once this model was created, the final model was designed by changing the continuous variable for number of transfusions to categorical variables (ie, 1-2 units, 3-4 units, and 5-7 units) if the continuous variable was significant. The final model was then used to determine factors predicting survival in 3 intervals: 0-12 years, 0-1 year, and 1-12 years. A post hoc analysis was performed when the statistical significance of suggested interaction from the different types of mismatch variables were tested in separate models, to avoid collinearity. In another post hoc analysis, all transfusion variables were forced in the final model to obtain effect estimates that were insignificant in the primary analysis. Kaplan-Meier curves were used to compare survival over time.

$\mathrm{R}$ version 2.13.0 with the survival package was used to test the proportional hazards assumption for a Cox regression model fit. All other statistical calculations were performed using Statistica version 12 (StatSoft, Tulsa, Okla).

\section{RESULTS}

\section{Study Population}

Patients were followed for 1 to 12 years (mean, 6.1 years). CABG was performed in 7696 patients $(77.7 \%)$, and AVR or AVR + CABG was performed in the other 2211 patients $(22.3 \%)$ (Table 1 and Figure E1). Among the patients, 5041
$(50.8 \%)$ received $\mathrm{RBC}$ transfusion, $2785(28.1 \%)$ received plasma transfusion, and $994(10.0 \%)$ received platelet transfusion (Table 2). The transfused patients had generally a worse postoperative outcome (Table 3). A total of 1920 deaths occurred during follow-up. Among the patients transfused with $\mathrm{RBCs}, 1596$ received only sex-mismatched RBCs and 876 received only sexmatched RBCs (Figures 1 and E2).

\section{Survival Analysis}

Stepwise elimination of nonsignificant variables in the Cox proportional hazards ratio analysis left 24 variables in the primary model (0-12 years). For the final model, leukocyte-depleted RBCs, non-leukocyte-depleted RBCs, and fresh plasma were entered as categorical variables (Table 4 and Figure 2). Fresh frozen plasma was not entered as a categorical variable because of the small number of observations. Transfusion of 5 to 7 units of leukocyte-depleted RBCs resulted in decreased survival, as did transfusion of sex-mismatched and Rh-matched RBCs (Table 4).

\section{One-Year Survival}

The final model was used to study mortality up to 1 year, yielding complete observations for the entire study cohort (219 deaths). Among transfusion variables, transfusion of 1 to 2 units of non-leukocyte-depleted RBCs and transfusion of more than 7 units of fresh plasma were associated with a significant increase in the hazard ratio (HR).

\section{One- to 12-Year Survival}

The analysis of survival during postoperative years 1-12 revealed 1701 deaths among 9688 patients analyzed. Among the transfusion variables, transfusion of 5-7 units of leukocyte-depleted RBCs, sex-mismatched RBCs, and $\mathrm{Rh}$-matched RBCs resulted in a significant increase in HR (Table 4).

\section{Post Hoc Analysis}

We performed a post hoc analysis to study the risks of transfusion-related risk factors in detail ( $0-12$ years). Rather than study simply sex mismatch in RBC transfusions, we entered sex mismatch as 2 continuous variables describing units of mismatch for each sex. In this analysis, the HR for receiving any RBCs was 1.050 per unit $(95 \%$ confidence interval [CI], 1.007-1.094; $P=.023$ ), and the excess HR for receiving sex-mismatched RBCs was 1.063 per unit $(95 \%$ CI, 1.004-1.125; $P<.033$ ). Analyzing men and women separately decreased the statistical precision. The excess HR for sex-mismatched RBCs was 1.078 per unit $(95 \%$ CI, $1.011-1.149 ; P=.022)$ in men and 1.046 per unit (95\% CI, 0.977-1.120; $P=.197$ ) in women (Figure 3).

The same operation was performed for $\mathrm{RBC} R \mathrm{Rh}$ mismatch. Receipt of any RBCs yielded an HR of 1.050 per unit (95\% CI, 1.007-1.094; $P=.023)$, and for receipt 
TABLE 1. Demographic data

\begin{tabular}{|c|c|c|c|}
\hline Variable & $\begin{array}{l}\text { All patients } \\
(\mathbf{n}=9907)\end{array}$ & $\begin{array}{c}\text { No } \mathrm{RBC} \text { transfusion } \\
(\mathrm{n}=\mathbf{4 8 6 6 )}\end{array}$ & $\begin{array}{c}\text { RBC transfusion } \\
\quad(\mathbf{n}=\mathbf{5 0 4 1})\end{array}$ \\
\hline Age, y, mean (SD) & $67.8(10.2)$ & $65.3(10)$ & $70.3(9.8)$ \\
\hline Female sex, $\mathrm{n}(\%)$ & $2545(26)$ & $702(14)$ & $1843(37)$ \\
\hline Diabetes, n $(\%)$ & $2117(21)$ & $1007(21)$ & $1110(22)$ \\
\hline COPD, n $(\%)$ & $1043(11)$ & $419(9)$ & $624(12)$ \\
\hline History of cerebrovascular disease, $\mathrm{n}(\%)$ & $891(9)$ & $349(7)$ & $542(11)$ \\
\hline Peripheral vascular disease, $\mathrm{n}(\%)$ & $1236(12)$ & $470(10)$ & $766(15)$ \\
\hline Neurological dysfunction, $\mathrm{n}(\%)$ & $155(2)$ & $64(1)$ & $91(2)$ \\
\hline Previous vascular surgery, $\mathrm{n}(\%)$ & $388(4)$ & $143(3)$ & $245(5)$ \\
\hline Previous cardiac surgery, n (\%) & $83(1)$ & $26(1)$ & $57(1)$ \\
\hline Previous PCI, n (\%) & $1123(11)$ & $583(12)$ & $540(11)$ \\
\hline Critical preoperative state, $\mathrm{n}(\%)$ & $287(3)$ & $82(2)$ & $205(4)$ \\
\hline Acute coronary syndrome, $\mathrm{n}(\%)$ & $2442(25)$ & $1172(24)$ & $1270(25)$ \\
\hline Acute myocardial infarction, $\mathrm{n}(\%)$ & $3794(38)$ & $1642(34)$ & $2152(43)$ \\
\hline Pulmonary hypertension, n (\%) & $166(2)$ & $52(1)$ & $114(2)$ \\
\hline LVEF $30 \%-50 \%, \mathrm{n}(\%)$ & $2471(25)$ & $1054(22)$ & $1417(28)$ \\
\hline $\mathrm{LVEF}<30 \%, \mathrm{n}(\%)$ & $624(6)$ & $219(5)$ & $405(8)$ \\
\hline Preoperative atrial fibrillation, $\mathrm{n}(\%)$ & $465(5)$ & $201(4)$ & $264(5)$ \\
\hline Preoperative dialysis, $\mathrm{n}(\%)$ & $157(2)$ & $59(1)$ & $98(2)$ \\
\hline Euroscore, additive, mean (SD) & $5(3.2)$ & $3.9(2.8)$ & $6(3.3)$ \\
\hline \multicolumn{4}{|l|}{ NYHA, n (\%) } \\
\hline I & $2311(23)$ & $1362(28)$ & 949 (19) \\
\hline II & $3345(34)$ & $1726(35)$ & $1619(32)$ \\
\hline III & $3257(33)$ & $1410(29)$ & $1847(37)$ \\
\hline IV & $993(10)$ & $368(8)$ & $625(12)$ \\
\hline \multicolumn{4}{|l|}{ CCS, n $(\%)$} \\
\hline I & $1204(12)$ & $616(13)$ & $588(12)$ \\
\hline II & $3507(35)$ & 1913 (39) & $1594(32)$ \\
\hline III & $3688(37)$ & $1751(36)$ & $1937(38)$ \\
\hline IV & $1435(14)$ & $554(11)$ & $881(17)$ \\
\hline \multicolumn{4}{|l|}{ Urgency, n (\%) } \\
\hline Elective (>1 wk), n (\%) & $6785(68)$ & $3529(73)$ & $3256(65)$ \\
\hline Prioritized (<1 wk), n (\%) & $2536(26)$ & $1112(23)$ & $1424(28)$ \\
\hline Urgent $(<24$ h), n $(\%)$ & $586(6)$ & $225(5)$ & $361(7)$ \\
\hline Body mass index, mean (SD) & $27.2(4.5)$ & $27.6(4)$ & $26.8(4.9)$ \\
\hline Preoperative hemoglobin, g/L, mean (SD) & $133.3(15.4)$ & $139.2(13.6)$ & $127.6(14.9)$ \\
\hline Preoperative leukocytes, 10e9/L, mean (SD) & $7.7(2.3)$ & $7.6(2)$ & $7.7(2.7)$ \\
\hline Preoperative CRP, mg/L, median (IQR) & $3(1.6-6.8)$ & $3(1.3-5)$ & $3(2.1-8.3)$ \\
\hline Preoperative creatinine, $\mu$ mol/L, mean (SD) & $87.8(45.8)$ & $83(27.8)$ & $92.5(57.8)$ \\
\hline Preoperative eGFR, $\mathrm{mL} / \mathrm{min} / 1.73 \mathrm{~m}^{2}$, mean $(\mathrm{SD})$ & $83.5(23.9)$ & $88.2(21.6)$ & $78.9(25.1)$ \\
\hline Preoperative ALT, $\mu$ kat $/ \mathrm{L}$, median (IQR) & $0.48(0.33-0.81)$ & $0.50(0.56-0.82)$ & $0.45(0.30-0.80)$ \\
\hline Preoperative AST, $\mu \mathrm{kat} / \mathrm{L}$, median (IQR) & $0.47(0.37-0.65)$ & $0.46(0.38-0.62)$ & $0.47(0.37-0.69)$ \\
\hline Preoperative platelets, $10 \mathrm{e} 9 / \mathrm{L}, \mathrm{n}(\%)$ & $236.9(65)$ & $231.3(58.1)$ & $242.3(70.7)$ \\
\hline CABG, $n(\%)$ & $7696(78)$ & $4046(83)$ & $3650(72)$ \\
\hline AVR, n $(\%)$ & $1216(12)$ & $581(12)$ & $635(13)$ \\
\hline $\mathrm{AVR}+\mathrm{CABG}, \mathrm{n}(\%)$ & 995 (10) & $239(5)$ & $756(15)$ \\
\hline Early era, 2002-2006, n (\%) & $4538(45.8)$ & $1978(40.6)$ & $2560(50.8)$ \\
\hline Late era, 2007-2012, n (\%) & $5369(54.2)$ & $2888(59.4)$ & $2481(49.2)$ \\
\hline
\end{tabular}

Shown are perioperative characteristics of the study population (all patients, patients not receiving RBC transfusion, and patients receiving RBC transfusion), presented as mean (SD) for continuous variables, median (IQR) for skewed variables, and number (\%) for dichotomous variables. RBC, Red blood cell; SD, standard deviation; COPD, chronic obstructive pulmonary disease; $P C I$, percutaneous coronary intervention; $L V E F$, left ventricular ejection fraction; NYHA, New York Heart Association; CCS, Canadian Cardiovascular Society; $C R P$, C-reactive protein; IQR, interquartile range; $e G F R$, estimated glomerular filtration rate; $A L T$, alanine aminotransferase; $A S T$, aspartate aminotransferase; $C A B G$, coronary artery bypass grafting; $A V R$, aortic valve replacement. 
TABLE 2. Transfusion data

\begin{tabular}{|c|c|c|}
\hline Variable & Mean $/$ median $/ \%$ & Total \\
\hline \multicolumn{3}{|l|}{$\mathrm{RBC}$ transfusion $(\mathrm{n}=5041)$} \\
\hline No RBC units transfused, mean (SD) & $2.9(1.6)$ & 14,797 \\
\hline LD units transfused, mean (SD) & $1.5(1.6)$ & 7738 \\
\hline Non-LD units transfused, mean (SD) & $1.4(1.6)$ & 7059 \\
\hline Cumulative storage time, $\mathrm{d}$, median (IQR) & $41(22-72)$ & $(1-281)$ \\
\hline Units older than $14 \mathrm{~d}$, mean $(\mathrm{SD})$ & $1.6(1.6)$ & 8084 \\
\hline Units with $\mathrm{ABO}$ mismatch, mean (SD) & $0.2(0.7)$ & 1099 \\
\hline Units with Rh mismatch, mean (SD) & $0.3(0.8)$ & 1295 \\
\hline Units with sex mismatch, mean (SD) & $1.7(1.3)$ & 8641 \\
\hline Units from female donor, mean (SD) & $0.9(1)$ & 4458 \\
\hline Units not in house, mean (SD) & $0.4(0.9)$ & 2064 \\
\hline Received also plasma, n (\%) & $2324(46)$ & \\
\hline Received also platelets, n (\%) & $841(17)$ & \\
\hline Received 1-2 units non-LD RBCs, n (\%) & $1815(36)$ & \\
\hline Received 3-4 units non-LD RBCs, n (\%) & $702(14)$ & \\
\hline Received 5-7 units non-LD RBCs, n (\%) & $283(6)$ & \\
\hline Received 1-2 units LD RBCs, n (\%) & $2054(41)$ & \\
\hline Received 3-4 units LD RBCs, n (\%) & $741(15)$ & \\
\hline Received 5-7 units LD RBCs, n (\%) & $158(3)$ & \\
\hline \multicolumn{3}{|l|}{ Plasma transfusion $(\mathrm{n}=2785)$} \\
\hline Units plasma transfused, mean (SD) & $3.7(3.5)$ & 10,224 \\
\hline Units fresh frozen plasma, mean (SD) & $0.2(0.6)$ & 479 \\
\hline Units fresh frozen plasma, mean (SD) & $0.2(0.6)$ & 479 \\
\hline Units fresh plasma, mean (SD) & $3.5(3.4)$ & 9719 \\
\hline Units Octaplas, mean (SD) & $0(0.2)$ & 26 \\
\hline Cumulative storage time, $\mathrm{d}$, median (IQR) & $24(13-49)$ & $(1-1801)$ \\
\hline Units older than $14 \mathrm{~d}$, mean (SD) & $0.4(1)$ & 1248 \\
\hline Units with $\mathrm{ABO}$ mismatch, mean (SD) & $0.7(1.6)$ & 1942 \\
\hline Units with Rh mismatch, mean (SD) & $0.3(0.8)$ & 756 \\
\hline Units with sex mismatch, mean (SD) & $1.6(1.8)$ & 4530 \\
\hline Units from female donor, mean (SD) & $1.4(1.6)$ & 3945 \\
\hline Units not in house, mean (SD) & $0(0.2)$ & 28 \\
\hline Received also RBCs, n (\%) & $2324(83)$ & \\
\hline Received also platelets, n (\%) & $718(26)$ & \\
\hline Received $1-2$ fresh plasma, n (\%) & $1423(51)$ & \\
\hline Received 3-4 fresh plasma, n (\%) & $650(23)$ & \\
\hline Received 5-7 fresh plasma, n (\%) & $359(13)$ & \\
\hline Received $>7$ fresh plasma, $\mathrm{n}(\%)$ & $250(9)$ & \\
\hline \multicolumn{3}{|l|}{ Platelet transfusion $(\mathrm{n}=994)$} \\
\hline Cumulative storage time, $\mathrm{d}$, median (IQR) & $10(6-14)$ & $(1-32)$ \\
\hline Units older than $7 \mathrm{~d}$, mean (SD) & $0.2(0.6)$ & 227 \\
\hline Units with $\mathrm{ABO}$ mismatch, mean (SD) & $0.4(0.9)$ & 414 \\
\hline Units with $\mathrm{Rh}$ mismatch, mean (SD) & $0.2(0.6)$ & 235 \\
\hline Units with sex mismatch, mean (SD) & $0.9(0.8)$ & 875 \\
\hline Units from female donor, mean (SD) & $0.7(0.7)$ & 718 \\
\hline Units not in house, mean (SD) & $0(0)$ & 2 \\
\hline Received also RBCs, n (\%) & $841(85)$ & \\
\hline Received also plasma, n (\%) & $718(72)$ & \\
\hline \multicolumn{3}{|l|}{ Patient blood group $(\mathrm{n}=9907)$} \\
\hline Patients with blood group $\mathrm{O}, \mathrm{n}(\%)$ & $3763(38)$ & \\
\hline Patients with blood group A, n (\%) & $4601(46)$ & \\
\hline Patients with blood group B, n (\%) & $1047(11)$ & \\
\hline Patients with blood group $\mathrm{AB}, \mathrm{n}(\%)$ & $489(5)$ & \\
\hline
\end{tabular}

(Continued)
TABLE 2. Continued

\begin{tabular}{ccc}
\hline Variable & Mean $/$ median $/ \%$ & Total \\
\hline Patients with $\mathrm{Rh}+, \mathrm{n}(\%)$ & $8270(83)$ & \\
Patients with $\mathrm{Rh}-, \mathrm{n}(\%)$ & $1631(16)$ & \\
\hline
\end{tabular}

Data are presented as mean (SD) number of units administered per transfused patient, median (IQR), or number (\%) of patients receiving or belonging to a group. The rightmost column shows the total number of transfusion or range for storage time. $R B C$, Red blood cell; $S D$, standard deviation; $L D$, leukocyte-depleted; non- $L D$, non-leukocyte-depleted; $I Q R$, interquartile range.

of $\mathrm{Rh}-$ mismatched RBCs, the excess HR was 0.932 per unit $(95 \% \mathrm{CI}, 0.876-0.992 ; P=.027)$. The excess HR for receiving Rh-mismatched RBCs was 0.931 per unit $(95 \%$ CI, 0.874-0.992: $P=.028$ ) for $\mathrm{Rh}+$ patients and 0.943 per unit $(95 \% \mathrm{CI}, 0.774-1.149 ; P=.56)$ for $\mathrm{Rh}-$ patients.

In a second post hoc analysis, we entered transfusionrelated risk factors that were eliminated in the stepwise elimination process into the final model. Only platelet storage days as a continuous variable, but not as a dichotomous variable, was significant (Table 5).

\section{DISCUSSION}

Here we report a study including almost 10,000 patients over a 12-year time period in which we attempted to encompass the complexity of blood transfusions by including sex-mismatched transfusions, blood group, age of blood products, and a broad selection of potential confounding risk factors. Our aim was to avoid study design bias by explicitly exploring a specific risk factor, and rather to examine the effects of all potential risk factors without preconceived ideas. Our main finding is the association between transfusion of sex-mismatched RBCs and decreased long-term survival. We also found that transfusion of small amounts of leukocyte-depleted RBCs was not associated with decreased long-term survival, whereas transfusion of small amounts of non-leukocyte-depleted RBCs was associated with decreased long-term survival.

The salient finding of this study is the consistent relationship between transfusion of sex-mismatched RBCs and decreased survival. In our post hoc analysis, sexmismatched RBCs had an excess HR of 1.046 to 1.133 per unit of mismatched blood transfused and was highly significant. In this cohort, $58 \%$ of transfusions were sex-mismatched, and thus we interpret the result as relatively robust and clinically relevant. A similar finding was reported by Middelburg and colleagues ${ }^{16}$ in a study of a more heterogeneous cohort. Moreover, sex mismatch is a well-known risk factor for decreased survival after heart transplantation. ${ }^{17}$ The explanation for this finding is only speculative at this time and merits further attention.

Blood transfusion in cardiac surgery has been a topic of debate. Previous studies have reported an association 
TABLE 3. Postoperative outcomes

\begin{tabular}{|c|c|c|c|}
\hline Variable & $\begin{array}{l}\text { All patients } \\
(\mathrm{n}=9907)\end{array}$ & $\begin{array}{c}\text { No } R B C \text { transfusion } \\
(n=4866)\end{array}$ & RBC transfusion $(n=5041)$ \\
\hline Perfusion time, min, mean (SD) & $88.8(34.4)$ & $81.3(30)$ & $96(36.8)$ \\
\hline Cross clamp time, min, mean (SD) & $56.8(27.4)$ & $51.9(24.1)$ & $61.6(29.5)$ \\
\hline Perfusion-cross clamp time, min, mean (SD) & $32(14)$ & $29.5(11.9)$ & $34.5(15.5)$ \\
\hline IABP preoperative, $\mathrm{n}(\%)$ & $207(2.1)$ & $62(1.3)$ & $145(2.9)$ \\
\hline IABP postoperative, $\mathrm{n}(\%)$ & $191(1.9)$ & $51(1)$ & $140(2.8)$ \\
\hline Hours in the ICU, median (IQR) & $22(19-25)$ & $22(19-24)$ & $23(21-39)$ \\
\hline Time on ventilator, min, median (IQR) & $360(245-530)$ & $300(215-425)$ & $400(290-670)$ \\
\hline Postoperative dialysis, $\mathrm{n}(\%)$ & $41(0.4)$ & $5(0.1)$ & $36(0.7)$ \\
\hline Postoperative bleeding, mL, mean (SD) & $786(553.6)$ & $667.2(346.7)$ & $900.7(677.9)$ \\
\hline Postoperative myocardial infarction, $\mathrm{n}(\%)$ & $106(1.1)$ & $29(0.6)$ & $77(1.5)$ \\
\hline Sepsis, n (\%) & $75(0.8)$ & $13(0.3)$ & $62(1.2)$ \\
\hline Permanent stroke, $\mathrm{n}(\%)$ & $44(0.4)$ & $13(0.3)$ & $31(0.6)$ \\
\hline Transient stroke, n (\%) & $62(0.6)$ & $16(0.3)$ & $46(0.9)$ \\
\hline New onset atrial fibrillation, $\mathrm{n}(\%)$ & $2293(23.1)$ & $922(18.9)$ & $1371(27.2)$ \\
\hline Reoperation for bleeding, n (\%) & $227(2.3)$ & $10(0.2)$ & $217(4.3)$ \\
\hline Postoperative mediastinitis, $\mathrm{n}(\%)$ & $102(1)$ & $36(0.7)$ & $66(1.3)$ \\
\hline 30-d mortality, n (\%) & $45(0.5)$ & $8(0.2)$ & $37(0.7)$ \\
\hline Total deaths in study, $\mathrm{n}(\%)$ & $1921(19.4)$ & $613(12.6)$ & $1308(25.9)$ \\
\hline
\end{tabular}

Data are presented as mean (SD) for continuous variables, median (IQR) for skewed variables, and number (\%) for dichotomous variables. $R B C$, Red blood cell; $S D$, standard deviation; $I A B P$, intra-aortic balloon pump; $I C U$, intensive care unit; $I Q R$, interquartile range.

between RBC transfusion and decreased survival. ${ }^{4,5,12,18-20}$ We previously showed that by entering more accurate measures for confounding risk factors, the risk associated with transfusion decreases and becomes no longer significant, but still with an HR above $1.0 .^{3,8,21}$ In this study, we included additional transfusion-related risk factors and comorbidities, and our findings indicate a further decrease in mortality risk, with an HR of 0.981 for receiving 1 to 2 units of leukocyte-depleted RBCs when adjusting for sex mismatch. The corresponding HR for non-leukocytedepleted RBCs was 1.109. Previous studies have shown increased short-term mortality and infection rates after transfusion with non-leukocyte-depleted RBCs. ${ }^{22,23}$

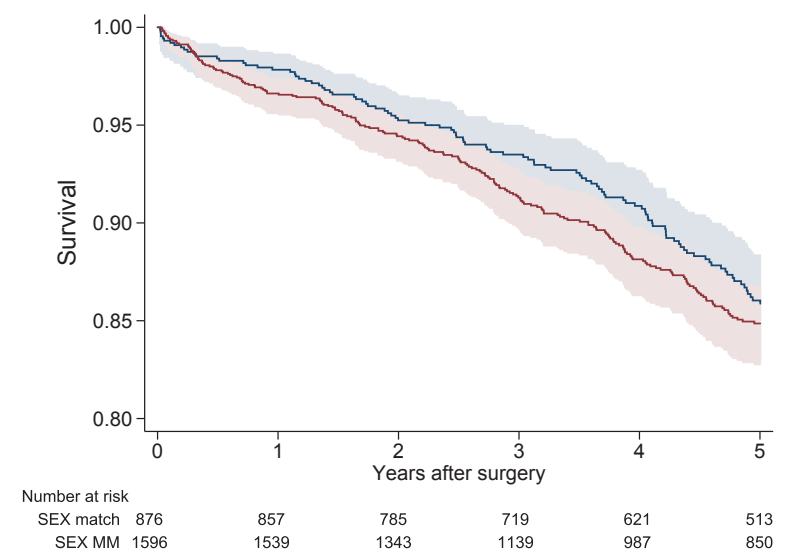

FIGURE 1. Kaplan-Meier curve comparing patients receiving only sex-matched blood (blue line) with only sex mismatched red blood cells (red line). Shaded area represents $95 \%$ confidence interval.
To highlight the importance of adjusting for confounders, we performed the analysis shown in Table 4 (0-12 years), but excluded all preoperative laboratory parameters (eGFR, CRP, hemoglobin, and leukocytes) and sex-mismatched blood (Figure 4). In the recently published randomized TITRe 2 study, the investigators found no increased short-term morbidity associated with a liberal threshold for transfusion after cardiac surgery. ${ }^{24}$ Interestingly, although it was not a primary variable, they even found decreased 90-day mortality in the liberally transfused group. It is, however, not known if leukocyte-depleted RBCs were used or not, but the findings are in line with our finding for leukocyte depleted RBCs. Our study revealed increased 1-year mortality after receipt of 1 to 2 units of non-leukocyte-depleted RBCs, but no increased mortality beyond 1 year. This puts our data in line with that reported in previous studies, but with the additional information that transfusion of small amounts of RBCs, leukocyte-depleted or not, is not associated with long-term mortality. A positive association between the amount of transfused RBCs and mortality was indicated for both non-leukocytedepleted and leukocyte-depleted RBCs (Figure 2). Patients receiving more than $2 \mathrm{RBC}$ units had a higher HR, but the accuracy of those estimates is unclear, given that the number of patients decreased considerably with the increasing number of transfusions; for example, the patients who received 57 units of leukocyte-depleted RBCs represent only $1.6 \%$ of the cohort (Table 2). 
TABLE 4. Results of Cox proportional hazard analysis

\begin{tabular}{|c|c|c|c|c|c|c|}
\hline \multirow[b]{2}{*}{ Variable } & \multicolumn{2}{|l|}{$0-12$ y } & \multicolumn{2}{|l|}{$0-1 y$} & \multicolumn{2}{|l|}{$1-12 y$} \\
\hline & HR & $\boldsymbol{P}$ & HR & $\boldsymbol{P}$ & HR & $P$ \\
\hline \multicolumn{7}{|l|}{ Transfusion factors } \\
\hline 1-2 units of non-LD RBCs* & $1.109(0.982-1.251)$ & .096 & $1.426(1.004-2.024)$ & .047 & $1.083(0.952-1.233)$ & .226 \\
\hline 3-4 units of non-LD RBCs* & $1.119(0.938-1.335)$ & .210 & $1.165(0.685-1.981)$ & .573 & $1.118(0.926-1.349)$ & .246 \\
\hline 5-7 units of non-LD RBCs* & $1.181(0.918-1.521)$ & .196 & $1.537(0.779-3.032)$ & .215 & $1.156(0.880-1.519)$ & .298 \\
\hline 1-2 units of LD RBCs* & $0.981(0.866-1.110)$ & .758 & $1.035(0.736-1.456)$ & .844 & $0.991(0.867-1.132)$ & .890 \\
\hline 3-4 units of LD RBCs* & $1.036(0.852-1.258)$ & .725 & $1.242(0.777-1.986)$ & .366 & $1.016(0.818-1.261)$ & .887 \\
\hline 5-7 units of LD RBCs* & $1.544(1.110-2.150)$ & .010 & $1.363(0.659-2.819)$ & .404 & $1.528(1.043-2.238)$ & .029 \\
\hline $1-2$ units of fresh plasma & $0.992(0.875-1.124)$ & .896 & $0.917(0.609-1.381)$ & .678 & $1.012(0.888-1.154)$ & .854 \\
\hline 3-4 units of fresh plasma & $1.026(0.869-1.211)$ & .760 & $0.903(0.541-1.507)$ & .696 & $1.077(0.905-1.280)$ & .404 \\
\hline 5-7 units of fresh plasma & $1.032(0.831-1.281)$ & .777 & $1.644(0.959-2.816)$ & .071 & $0.987(0.779-1.249)$ & .910 \\
\hline$>7$ units of fresh plasma & $1.124(0.876-1.442)$ & .358 & $2.127(1.233-3.670)$ & .007 & $1.002(0.758-1.324)$ & .989 \\
\hline Fresh frozen plasma (per unit) & $1.002(0.898-1.118)$ & .972 & $1.142(0.912-1.429)$ & .249 & $0.968(0.853-1.098)$ & .614 \\
\hline Platelets (per unit) & $0.967(0.898-1.042)$ & .378 & $0.873(0.716-1.065)$ & .180 & $0.987(0.910-1.069)$ & .741 \\
\hline $\mathrm{RBC} \mathrm{Rh}$ mismatch $\dagger$ & $0.928(0.870-0.989)$ & .021 & $0.962(0.810-1.142)$ & .657 & $0.928(0.866-0.994)$ & .033 \\
\hline $\mathrm{RBC}$ sex mismatch $\dagger$ & $1.083(1.028-1.140)$ & .003 & $1.133(0.996-1.289)$ & .057 & $1.076(1.016-1.139)$ & .012 \\
\hline \multicolumn{7}{|l|}{ Preoperative risk factors } \\
\hline Age (y) & $1.057(1.051-1.064)$ & $<.001$ & $1.038(1.020-1.057)$ & $<.001$ & $1.060(1.053-1.067)$ & $<.001$ \\
\hline Diabetes & $1.494(1.346-1.658)$ & $<.001$ & $1.377(1.019-1.861)$ & .038 & $1.505(1.346-1.681)$ & $<.001$ \\
\hline COPD & $1.589(1.407-1.795)$ & $<.001$ & $1.534(1.103-2.134)$ & .011 & $1.583(1.389-1.805)$ & $<.001$ \\
\hline Female & $0.788(0.705-0.879)$ & $<.001$ & $1.078(0.788-1.475)$ & .639 & $0.758(0.674-0.853)$ & $<.001$ \\
\hline Peripheral vascular disease & $1.610(1.441-1.799)$ & $<.001$ & $1.544(1.124-2.120)$ & .007 & $1.608(1.428-1.811)$ & $<.001$ \\
\hline Acute coronary syndrome & $0.765(0.643-0.910)$ & .003 & $0.877(0.538-1.431)$ & .600 & $0.778(0.646-0.937)$ & .008 \\
\hline $\mathrm{EF} 30 \%-50 \%$ & $1.351(1.221-1.494)$ & $<.001$ & $1.670(1.223-2.280)$ & .001 & $1.320(1.186-1.469)$ & $<.001$ \\
\hline $\mathrm{EF}<30 \%$ & $2.004(1.723-2.332)$ & $<.001$ & $2.533(1.706-3.759)$ & $<.001$ & $1.958(1.659-2.310)$ & $<.001$ \\
\hline \multicolumn{7}{|l|}{ Perioperative variable } \\
\hline Perfusion time & $1.002(1.001-1.003)$ & .003 & $1.001(0.998-1.005)$ & .425 & $1.002(1.001-1.004)$ & .004 \\
\hline Aortic valve replacement & $1.210(1.038-1.412)$ & .015 & $1.582(1.084-2.309)$ & .017 & $1.159(0.979-1.372)$ & .087 \\
\hline Permanent stroke & $1.737(1.074-2.808)$ & .024 & $3.051(1.115-8.344)$ & .030 & $1.532(0.885-2.653)$ & .128 \\
\hline Reoperation for bleeding & $0.568(0.396-0.816)$ & .002 & $0.681(0.307-1.515)$ & .347 & $0.568(0.379-0.851)$ & .006 \\
\hline Log time on ventilator & $1.128(1.057-1.205)$ & $<.001$ & $1.370(1.198-1.567)$ & $<.001$ & $1.068(0.992-1.150)$ & .080 \\
\hline \multicolumn{7}{|l|}{ Preoperative laboratory parameters } \\
\hline Preoperative hemoglobin & $0.992(0.989-0.995)$ & $<.001$ & $0.996(0.986-1.005)$ & .380 & $0.992(0.988-0.995)$ & $<.001$ \\
\hline Preoperative leukocyte count & $1.034(1.018-1.049)$ & $<.001$ & $1.005(0.955-1.057)$ & .847 & $1.037(1.021-1.053)$ & $<.001$ \\
\hline Log preoperative CRP & $1.098(1.056-1.143)$ & $<.001$ & $1.271(1.141-1.417)$ & $<.001$ & $1.071(1.026-1.117)$ & .002 \\
\hline Preoperative eGFR & $0.991(0.989-0.994)$ & $<.001$ & $0.988(0.981-0.995)$ & .001 & $0.992(0.989-0.994)$ & $<.001$ \\
\hline
\end{tabular}

$H R$, Hazard ratio; non- $L D$, non-leukocyte-depleted; $R B C$, red blood cell; $L D$, leukocyte-depleted; $C O P D$, chronic obstructive pulmonary disease; $E F$, ejection fraction; $C R P$, $\mathrm{C}$-reactive protein; $e G F R$, estimated glomerular filtration rate. *Denotes total number of RBC transfusions. †Denotes excess risk (related to the RBC transfusion risk only).

We also tested the significance of mismatch in terms of $\mathrm{Rh}$ compatibility between donor and recipient. A positive survival benefit was found for Rh-mismatched RBCs; however, the frequency of Rh mismatch was low and increased with the number of transfusions. In our department, Rh-mismatched blood is transfused if the stock of $\mathrm{Rh}$-matched blood is low, and thus Rh-mismatched blood is given predominantly to patients who experience a single episode of heavy bleeding. Consequently, Rh-matched blood is more often given to patients requiring transfusions over several days. This difference in transfusion indication could explain the positive effects of Rh-mismatched blood, with transfusion for surgical bleeding is not associated with adverse outcomes. For these reasons, the statistical relationship found for $\mathrm{Rh}$ mismatch should be interpreted with caution.

In general, plasma transfusion was not associated with adverse outcomes. Although we previously reported an association between plasma transfusion and long-term outcomes, ${ }^{21}$ in the present analysis plasma transfusions were categorized and studied at different time intervals. Plasma-associated mortality was found only during the first year and for numerous transfusions, which does not contradict earlier findings when transfusion was presented as a continuous variable.

The present study included a variety of transfusion variables in the analysis that were not associated with increased long-term mortality, and these results are 


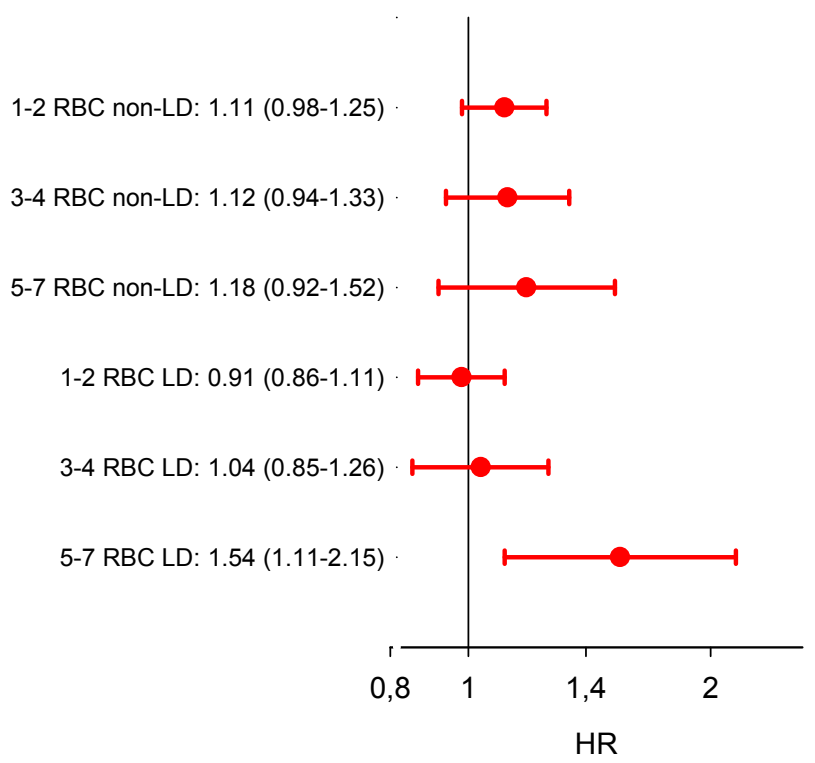

FIGURE 2. Forest plot for RBC transfusion risk (0-12 years) in categories with HR ( $95 \%$ CI). RBC, Red blood cell; non- $L D$, non-leukocyte-depleted RBC unit; $L D$, leukocyte-depleted RBC unit; $H R$, hazard ratio.

important in terms of transfusion safety. For instance, no association between age of blood products and survival was found. Large studies have shown such an association, ${ }^{4}$ but later, more well-controlled studies have disputed such an association. ${ }^{25-28}$ Another debated factor that was not associated with adverse outcome in our study is plasma from female donors. Several reports have linked plasma from female donors to both an increased frequency of transfusion-related lung

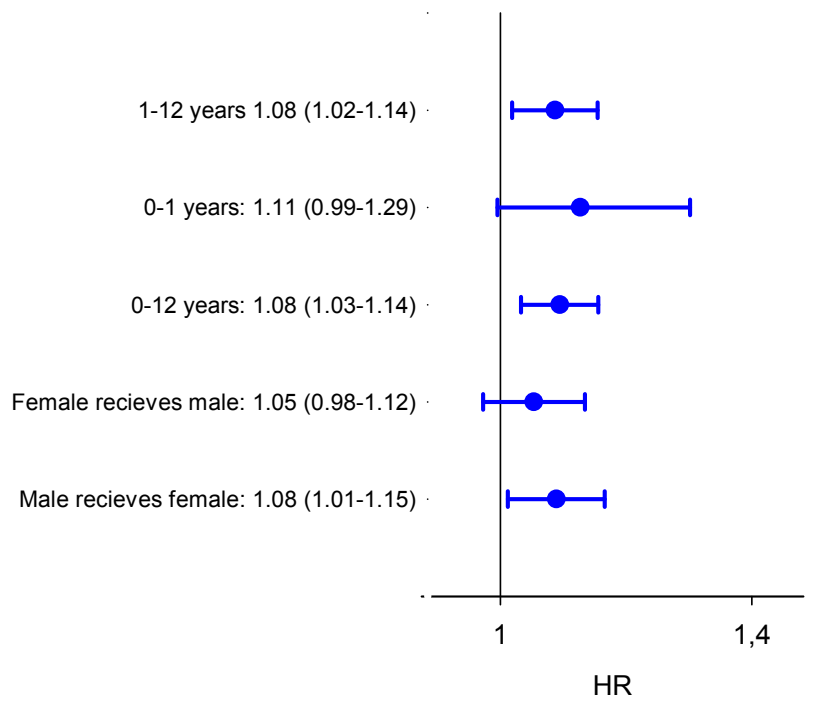

FIGURE 3. Forest plot for excess mortality risk for sex-mismatched RBCs expressed as HR $(95 \% \mathrm{CI})$ for different time intervals and sex of recipient (0-12 years). $H R$, Hazard ratio.

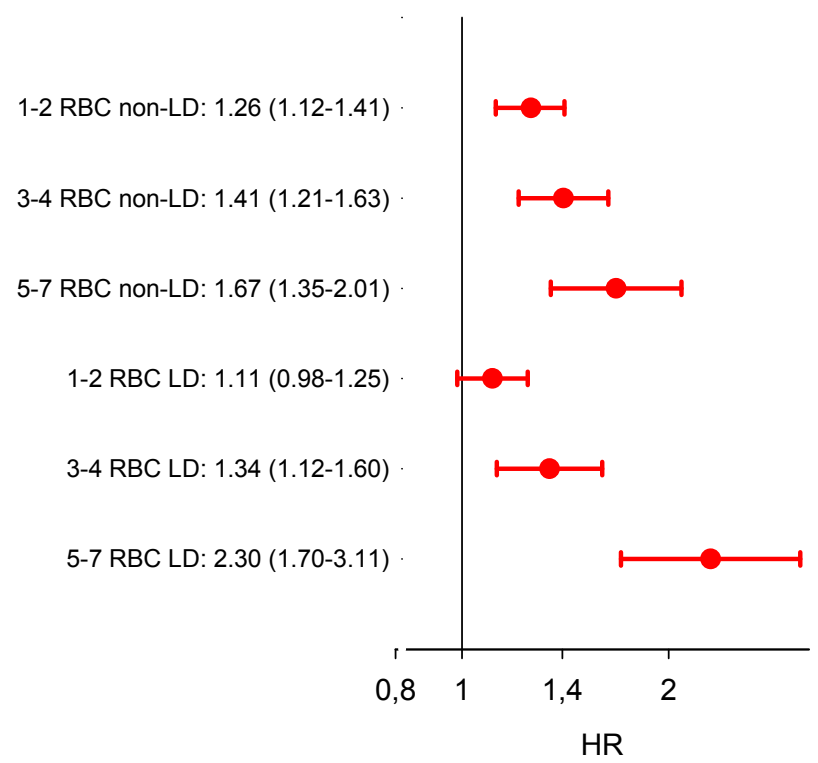

FIGURE 4. Forest plot for RBC transfusion risk (0-12 years) in categories with HR $(95 \% \mathrm{CI})$ without preoperative laboratory parameters (eGFR, CRP, hemoglobin, and leukocytes) and sex mismatched blood in the Cox analysis. $R B C$, Red blood cell; non- $L D$, non-leukocyte-depleted RBC unit; $L D$, leukocyte-depleted $\mathrm{RBC}$ unit; $H R$, hazard ratio.

injury and increased short-term mortality ${ }^{29,30}$; however, both of those studies focused on short-term outcomes, and neither contradict the findings of the present study. Moreover, transfusion outside the patient's blood group did not affect survival for any blood product, and the patient's own blood group or Rh status did not affect survival. Only the age of platelets was significant; however, this could be a false-positive finding in the post hoc analysis, especially because the other measure of platelet age was not significant.

In this study, we aimed to describe the clinical outcome (ie, mortality), with a focus on transfusion-related risk factors but also including many clinical risk factors-a retrospective observational study. Therefore, the incidence of transfusions mirrors the clinical reality, not a predefined study protocol. In our study, $50.8 \%$ of the patients received any RBC transfusion, compared with $66.7 \%$ in the group with a restrictive transfusion threshold (ie, hemoglobin $<75 \mathrm{~g} / \mathrm{dL}$ ) reported in the study by Murphy and colleagues. ${ }^{24}$ In addition, the distribution of the units given to our patients is very similar to that reported by Murphy and colleagues.

A notable finding is the more severe disease burden before surgery in our patients receiving RBC transfusions (Table 1). Perioperatively, the RBC transfusion group had a more complicated situation with longer perfusion and cross-clamp times; however, this might be the result of overrepresentation of AVR + CABG in the group receiving $\mathrm{RBC}$ transfusions. As anticipated, there were 
TABLE 5. Results of post hoc analysis

\begin{tabular}{|c|c|c|}
\hline Variable & HR & $P$ value \\
\hline \multicolumn{3}{|l|}{ Transfusion } \\
\hline $\mathrm{RBCs}>14 \mathrm{~d}$ & $1.04(0.98-1.11)$ & .210 \\
\hline RBC storage (d/10) & $0.99(0.97-1.02)$ & .719 \\
\hline $\mathrm{RBC}$ female donor & $1.00(0.92-1.08)$ & .947 \\
\hline RBC ABO mismatch & $1.04(0.92-1.17)$ & .543 \\
\hline $\mathrm{RBC}$ out of house & $1.03(0.94-1.13)$ & .506 \\
\hline \multicolumn{3}{|l|}{ Platelet transfusion } \\
\hline Platelets $>7 \mathrm{~d}$ & $1.05(0.72-1.52)$ & .806 \\
\hline Platelet storage (d) & $0.63(0.41-0.98)$ & .041 \\
\hline Platelets $\mathrm{ABO}$ mismatch & $0.90(0.75-1.09)$ & .279 \\
\hline Platelets Rh mismatch & $1.09(0.83-1.42)$ & .537 \\
\hline Platelets sex mismatch & $0.88(0.69-1.12)$ & .311 \\
\hline Platelets female donor & $1.18(0.92-1.52)$ & .202 \\
\hline \multicolumn{3}{|l|}{ Plasma transfusion } \\
\hline Plasma $>14 \mathrm{~d}$ & $1.07(0.98-1.16)$ & .142 \\
\hline Plasma storage (d/10) & $1.00(0.99-1.01)$ & .984 \\
\hline Plasma ABO mismatch & $1.01(0.96-1.05)$ & .779 \\
\hline Plasma Rh mismatch & $1.08(0.99-1.18)$ & .076 \\
\hline Plasma sex mismatch & $0.95(0.88-1.01)$ & .112 \\
\hline Plasma female donor & $1.05(0.98-1.12)$ & .189 \\
\hline Plasma out of house & $0.74(0.40-1.37)$ & .340 \\
\hline \multicolumn{3}{|l|}{ Patient blood group } \\
\hline Patient blood group A & $0.97(0.88-1.08)$ & .603 \\
\hline Patient blood group B & $1.05(0.89-1.24)$ & .569 \\
\hline Patient blood group $\mathrm{AB}$ & $0.84(0.66-1.07)$ & .167 \\
\hline Patient $\mathrm{Rh}+$ & $1.01(0.89-1.16)$ & .846 \\
\hline
\end{tabular}

increased postoperative bleeding and number of reoperations for bleeding in the RBC transfusion group. Nonetheless, the advanced preoperative disease in the same group suggests other causes than transfusion-related for the increased mortality. This interpretation is supported by the generally higher HR with greater statistical strength in such risk factors as age, diabetes, COPD, and cardiac insufficiency compared with transfusionrelated variables (Table 4). This suggests that blood transfusion in part is a biomarker for advanced disease. Interestingly, there was no obvious difference in ICU time between transfused and nontransfused patients. This implies that although the RBC transfusion recipients were sicker and suffered a higher mortality, they did not require more ICU care.

This study has some limitations. Despite the sizable number of patients, a larger cohort could help us identify a more nuanced relationship between transfusion and outcome. Any retrospective study has inherent weaknesses in controlling for confounding variables. The single-center design is both a disadvantage and an advantage. A multicenter study would have yielded a larger cohort with a more representative population. However, the single-center design does reduce the variation in many background parameters and also provides the opportunity to retrieve as detailed information as possible on transfusion and confounding risk factors. The fact that we managed to enter several laboratory and clinical parameters that normally are not explored in transfusion studies resulted in a model in which eGFR, preoperative hemoglobin, CRP, and leukocyte count were identified as highly significant predictors. These are factors that otherwise could interfere with the transfusion analysis, skewing the results for transfusion risk. Because we excluded deaths occurring within 1 week of surgery (the period when most transfusions are performed), any transfusion reactions that could be directly or indirectly fatal were not accounted for in this study. The study evaluated a longer period of time, and temporal biases could affect the results. We included a variable for late and early era in the analysis, which proved nonsignificant, but this does not exclude the possibility of a temporal effect.

In conclusion, in our cohort, sex-mismatched RBC transfusion was associated with increased long-term mortality. Transfusion of smaller amounts of leukocytedepleted RBCs was not associated with adverse outcomes, but transfusion of non-leukocyte-depleted RBCs was associated with increased mortality in the short term. The findings of this study could contribute to the debate on transfusion risks in cardiac surgery and generate hypotheses for controlled trials in the future.

\section{Conflict of Interest Statement}

Dr Algotsson reports lecture fees from Abbott. Dr Bjursten reports consulting fees from Boston Scientific. All other authors have nothing to disclose with regard to commercial support.

\section{References}

1. Gerber DR. Risks of packed red blood cell transfusion in patients undergoing cardiac surgery. J Crit Care. 2012;27:737.e1-9.

2. Murad MH, Stubbs JR, Gandhi MJ, Wang AT, Paul A, Erwin PJ, et al. The effect of plasma transfusion on morbidity and mortality: a systematic review and metaanalysis. Transfusion. 2010;50:1370-83.

3. Bjursten H, Al-Rashidi F, Dardashti A, Brondén B, Algotsson L, Ederoth P. Risks associated with the transfusion of various blood products in aortic valve replacement. Ann Thorac Surg. 2013;96:494-9.

4. Koch CG, Li L, Sessler DI, Figueroa P, Hoeltge GA, Mihaljevic T, et al. Duration of red-cell storage and complications after cardiac surgery. $N$ Engl J Med. 2008; 358:1229-39.

5. Koch CG, Li L, Duncan AI, Mihaljevic T, Loop FD, Starr NJ, et al. Transfusion in coronary artery bypass grafting is associated with reduced long-term survival. Ann Thorac Surg. 2006;81:1650-7.

6. Jakobsen CJ, Ryhammer PK, Tang M, Andreasen JJ, Mortensen PE. Transfusion of blood during cardiac surgery is associated with higher long-term mortality in low-risk patients. Eur J Cardiothorac Surg. 2012;42:114-20.

7. Statistics Sweden. Migrations by region, age, gender and years [in Swedish] Available at: www.scb.se. Accessed May 15, 2014.

8. Dardashti A, Ederoth P, Algotsson L, Brondén B, Lührs C, Bjursten H. Blood transfusion after cardiac surgery: is it the patient or the transfusion that carries the risk? Acta Anaesthesiol Scand. 2011;55:952-61.

9. Levey AS, Stevens LA, Schmid CH, Zhang YL, Castro AF III, Feldman HI, et al. A new equation to estimate glomerular filtration rate. Ann Intern Med. 2009;150: 604-12. 
10. Engoren M, Arslanian-Engoren C. Long-term survival in the intensive care unit after erythrocyte blood transfusion. Am J Crit Care. 2009;18:124-31.

11. Koch CG, Li L, Duncan AI, Mihaljevic T, Cosgrove DM, Loop FD, et al. Morbidity and mortality risk associated with red blood cell and bloodcomponent transfusion in isolated coronary artery bypass grafting. Crit Care Med. 2006;34:1608-16.

12. Kuduvalli M, Oo AY, Newall N, Grayson AD, Jackson M, Desmond MJ, et al. Effect of peri-operative red blood cell transfusion on 30-day and 1-year mortality following coronary artery bypass surgery. Eur J Cardiothorac Surg. 2005;27: 592-8.

13. Brown JR, Cochran RP, MacKenzie TA, Furnary AP, Kunzelman KS, Ross CS, et al. Long-term survival after cardiac surgery is predicted by estimated glomerular filtration rate. Ann Thorac Surg. 2008;86:4-11.

14. Hobson CE, Yavas S, Segal MS, Schold JD, Tribble CG, Layon AJ, et al. Acute kidney injury is associated with increased long-term mortality after cardiothoracic surgery. Circulation. 2009;119:2444-53.

15. Hillis GS, Croal BL, Buchan KG, El-Shafei H, Gibson G, Jeffrey RR, et al. Renal function and outcome from coronary artery bypass grafting: impact on mortality after a 2.3-year follow-up. Circulation. 2006;113: 1056-62.

16. Middelburg RA, Briët E, van der Bom JG. Mortality after transfusions, relation to donor sex. Vox Sang. 2011;101:221-9.

17. Khush KK, Kubo JT, Desai M. Influence of donor and recipient sex mismatch on heart transplant outcomes: analysis of the International Society for Heart and Lung Transplantation Registry. J Heart Lung Transplant. 2012; 31:459-66.

18. Engoren MC, Habib RH, Zacharias A, Schwann TA, Riordan CJ, Durham SJ. Effect of blood transfusion on long-term survival after cardiac operation. Ann Thorac Surg. 2002;74:1180-6.

19. Bhaskar B, Dulhunty J, Mullany DV, Fraser JF. Impact of blood product transfusion on short and long-term survival after cardiac surgery: more evidence. Ann Thorac Surg. 2012:94:460-7.

20. Paone G, Likosky DS, Brewer R, Theurer PF, Bell GF, Cogan CM, et al. Transfusion of 1 and 2 units of red blood cells is associated with increased morbidity and mortality. Ann Thorac Surg. 2014;97:87-93.
21. Bjursten H, Dardashti A, Ederoth P, Brondén B, Algotsson L. Increased longterm mortality with plasma transfusion after coronary artery bypass surgery. Intensive Care Med. 2013;39:437-44.

22. Bilgin YM, van de Watering LM, Eijsman L, Versteegh MI, Brand R, van Oers $\mathrm{MH}$, et al. Double-blind, randomized controlled trial on the effect of leukocyte-depleted erythrocyte transfusions in cardiac valve surgery. Circulation. 2004;109:2755-60.

23. van de Watering LM, Hermans J, Houbiers JG, van den Broek PJ, Bouter H, Boer F, et al. Beneficial effects of leukocyte depletion of transfused blood on postoperative complications in patients undergoing cardiac surgery: a randomized clinical trial. Circulation. 1998;97:562-8.

24. Murphy GJ, Pike K, Rogers CA, Wordsworth S, Stokes EA, Angelini GD, et al. Liberal or restrictive transfusion after cardiac surgery. N Engl J Med. 2015;372: 997-1008.

25. Edgren G, Kamper-Jorgensen M, Eloranta S, Rostgaard K, Custer B, Ullum H, et al. Duration of red blood cell storage and survival of transfused patients. Transfusion. 2010;50:1185-95.

26. Steiner ME, Ness PM, Assmann SF, Triulzi DJ, Sloan SR, Delaney M, et al. Effects of red-cell storage duration on patients undergoing cardiac surgery. $N$ Engl $J$ Med. 2015;372:1419-29.

27. McKenny M, Ryan T, Tate H, Graham B, Young VK, Dowd N. Age of transfused blood is not associated with increased postoperative adverse outcome after cardiac surgery. Br J Anaesth. 2011;106:643-9.

28. Lacroix J, Hébert PC, Fergusson DA, Tinmouth A, Cook DJ, Marshall JC, et al. Age of transfused blood in critically ill adults. N Engl J Med. 2015;372:1410-8.

29. Chapman CE, Stainsby D, Jones H, Love E, Massey E, Win N, et al. Ten years of hemovigilance reports of transfusion-related acute lung injury in the United Kingdom and the impact of preferential use of male donor plasma. Transfusion. 2009; 49:440-52.

30. Tynell E, Andersson TM, Norda R, Edgren G, Nyren O, Shanwell A, et al. Should plasma from female donors be avoided? A population-based cohort study of plasma recipients in Sweden from 1990 through 2002. Transfusion. 2010;50:1249-56.

Key Words: transfusion, survival, sex mismatch, CABG 


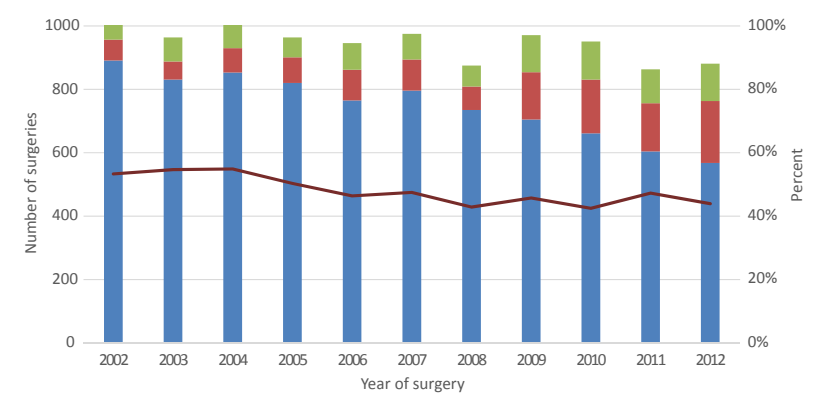

FIGURE E1. Distribution during the study period of number of CABG (blue bar), AVR (red bar), and AVR + CABG (green bar). Transfusion rate as percent of patients receiving $\mathrm{RBC}$ transfusion (dark red line).

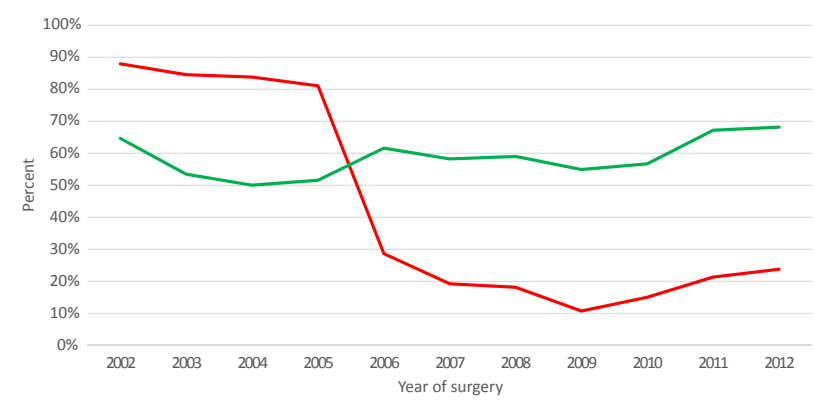

FIGURE E2. Percentage of sex mismatched RBC transfusion (green line), and percentage non leukocyte depleted RBC (red line). 